\title{
Factibilidad de un proyecto avícola para producción de huevos bajo sistema free-range en el sur de Chile
}

\author{
Feasibility of a Project for poultry egg production system under Free-range in \\ Southern Chile
}

\author{
Angélica Rosas N. ${ }^{1}$, Juan Lerdon F. ${ }^{*}$
}

\begin{abstract}
RESUMEN
El mercado avícola en los últimos años ha crecido enormemente tanto a nivel internacional como nacional, por ende la producción de huevos va en aumento. Históricamente esta producción se ha llevado a cabo convencionalmente, es decir a través de jaulas. Esto ha cambiado por una creciente preocupación en muchos países por el confinamiento y bienestar de las gallinas ponedoras, dando lugar a nuevos sistemas de producción como el free-range.

El presente estudio determina la factibilidad técnica-económica de un proyecto avícola para la producción de huevos bajo sistema free-range en la comuna de Río Negro. Se realizó un resumen del mercado y un estudio técnico, financiero y económico de la producción de huevos en Chile.
\end{abstract}

Palabras claves: huevos, gallinas ponedoras, free-range, bienestar

\section{ABSTRACT}

The poultry market in recent years has grown enormously both internationally and nationally, hence the production of eggs is increasing, historically this production has been carried out conventionally, ie through cages. This has been changed by growing concern in many countries over the confinement and welfare of laying hens, resulting in new production systems such as free-range. The present study determines the technical-economic feasibility of a poultry project for the production of eggs under a free-range system in the commune of Río Negro, carrying out a market summary, a technical, financial and economic study of the production of eggs in Chile.

Keywords: Eggs, laying hens, free-range, welfare

\section{Introducción}

Mench, Swansony Thompson(2009), indicanque existe una creciente preocupación en muchos países por el confinamiento de las gallinas ponedoras en los sistemas de alojamiento conductualmente restrictivos, como las jaulas convencionales. Por esto, un número cada vez mayor de huevos se están produciendo en los sistemas de alojamiento alternativos en algunos países. Aunque el sistema de producción en jaulas convencionales sigue siendo predominante en todo el mundo para las gallinas ponedoras, la preocupación ética sobre el grado de restricción del comportamiento de estas aves, ha dado lugar a un movimiento creciente hacia los sistemas alternativos, impulsado también por las preferencias de compra de los consumidores y por las legislaciones.

Según lo indicado por Callejos (2012), el bienestar animal es un aspecto de la producción pecuaria que ha adquirido de enorme importancia en la Unión Europea (UE) en los últimos 10-15 años, lo que ha dado lugar a una amplia legislación, tanto en lo que concierne a manejo y condiciones

* Universidad Austral de Chile, Facultad de Ciencias Agrarias, Instituto de Economía Agraria, Casilla 567, Valdivia.

* Autor por correspondencia: jlerdon@uach.cl 
de los alojamientos a condiciones de transporte de animales y de sacrificio. El objetivo de esta normativa es evitar sufrimientos innecesarios a los animales y darles la oportunidad, en la medida de lo posible, de que puedan expresar pautas naturales de conducta. También ha ido en aumento la demanda de los consumidores de alimentos y productos de origen animal obtenidos en modelos de producción éticamente correctos.

Uno de los sistemas desarrollados sin jaulas es el free-range, sobre el cual, Albarrán, Cruz-Coke y Gandarillas (2011), indican que su objetivo es la obtención de alimentos de alta calidad, con óptima utilización de recursos, respeto al medio ambiente y aprovechamiento del guano para fertilización. La base de este sistema alternativo es que las adaptaciones realizadas provean a las aves de un buen lugar de alojamiento, un manejo apropiado y una composición de alimentos adecuada.

Giacomozzi (2014) indica que en Chile el mercado avícola esta orientado a la producción de carne y de huevos, desarrollándose este último producto en forma considerable con el paso del tiempo. Las empresas con mayor participación son 11 , las cuales abarcan el $66 \%$ aproximadamente de la producción en Chile. No obstante, los productores que existen hoy en día son muchos más. Según la Asociación Gremial de Productores de Huevos de Chile (ASOHUEVO) (2016), los asociados son 35 , concentrándose en las regiónes de Valparaíso y Metropolitana. No existiendo ninguno de ellos en la región de Los Lagos. Además, estos productores utilizan los sistemas convencionales, por lo que un proyecto de sistema alternativo asociado al bienestar animal puede ser factible.

Este estudio analiza la producción de huevos a nivel nacional y mundial. Evalúa en un predio de la comuna de Río Negro, la factibilidad económica y financiera de dos niveles de producción de huevos. Para lo cual estima los ingresos y costos de la producción con una visión futura, evalúa su rentabilidad y los manejos necesarios para mejorar las utilidades y optimizar los recursos en el tiempo, con los respectivos riesgos asociados.

\section{Materiales y métodos}

Para el análisis y desarrollo del estudio se utilizó información secundaria obtenida de fuentes como ODEPA, INE, FAO, ASOHUEVO y revistas científicas, e información primaria recolectada de un productor de huevos de la Región de Los Lagos.

Lo anterior, permitió determinar el tamaño y localización del predio, considerando en el tamaño factores como la superficie trabajada $\left(256 \mathrm{~m}^{2} \mathrm{de}\right.$ gallinero y $2.348 \mathrm{~m}^{2}$ de patio de recreación), y la cantidad de gallinas (400 0700 gallinas Lohmann Brown). En relación a la localización, se analizan las variables como el tipo de suelo, clima y vegetación.

El estudio financiero evalúa dos planes de inversión para el plantel avícola y la producción de huevos: compra de 400 y 700 gallinas respectivamente, así como los ingresos y costos asociados, clasificados en fijos y variables.

A partir de esta información, se elaboró la proyección de fuentes y uso de fondos y el flujo de ingresos y costos para la evaluación financiera, basándose esta última en la rentabilidad e indicadores económicos.

\section{Resultados y discusión}

\section{Tamaño del proyecto}

El tamaño del proyecto es medianamente pequeño. Contempla un gallinero de 8 metros de ancho y 32 metros de largo, lo que implica un área total de $256 \mathrm{~m}^{2}$, equipado con comederos, bebederos, sistema de iluminación, etc. Esta infraestructura se ubica en una superficie de terreno de $2.348 \mathrm{~m}^{2}$, que considera un patio de recreación y alimentación durante el día para las 400 y 700 gallinas que contempla el proyecto.

\section{Descripción del sistema productivo}

La producción se llevará a cabo utilizando el sistema alternativo o free-range, el cual tiene como objetivo la obtención de huevos de alta calidad, con óptimo manejo de las gallinas para su bienestar y un bajo impacto al medio ambiente, debido al aprovechamiento del guano para fertilización. Para ello el proyecto consta de un gallinero equipado, el cual provee a las aves de un lugar de alojamiento, un manejo apropiado y una correcta alimentación.

Los dos niveles de producción evaluados se implementan con las 400 o 700 gallinas de raza Lohmann Brown respectivamente, listas para la puesta de huevos. Se escogió esta raza por su rusticidad, ya que producen adecuadamente en diferentes condiciones climáticas, tienen buena 
respuesta al consumo de alimento, incluso bajo condiciones adversas de temperatura. Además, alcanzan de manera rápida un buen tamaño del huevo, con un promedio de peso bastante competitivo y sin producir huevos demasiado grandes que causen efectos negativos (Anastasov, 2014).

La recolección de huevos se realiza dos veces al día en forma manual, tanto en la mañana como en la tarde, al igual que la alimentación. Se consumen 100 g/gallina diarios de concentrado, compuesto de maíz en mayor porcentaje, además de conchuelas y vitaminas. Esto acompañado de bebederos, siendo de suma importancia que beban agua para la obtención del huevo. En verano tendrán 4 horas de luz adicionales y en invierno se aumentara a 7 horas de luz, esto para mantener el nivel de producción de huevos.

El empaquetamiento será de 12 unidades o en bandejas de 30 unidades. La venta del producto se realizará en la ciudad de Río Negro, pues la persona encargada llevará los huevos de lunes a sábado para su distribución, para lo cual se determinó el gasto en bencina, cambio de aceite y cambio de neumáticos en los costos totales que se detallan más adelante. Además, el cliente puede ir a comprar el producto al mismo lugar de las instalaciones, si lo desea.

\section{Descripción del plan de inversión}

La primera inversión consiste en 400 gallinas por cada ciclo productivo, con un valor unitario de \$4.980. Estas se compran en la Avícola Santa Fe en Osorno, lo que genera un costo de inversión de \$7.968.000. También se debe incluir en la inversión inicial la compra de gallinas de reposición, como el proyecto durara siete años se debe comprar gallinas en el segundo, cuarto y sexto año. El valor de los nidos entre mano de obra y madera es de $\$ 210.000$; dentro del costo de la construcción del gallinero esta incluida la madera que se utiliza, las latas de zinc, los comederos, bebederos, perchas, bodega de alimento, piso de cemento, sistema eléctrico y mano de obra, y por último el cerco que rodeará el patio de recreación de las gallinas. La fuente de financiamiento es un crédito a largo plazo solicitado a una institución bancaria (Tabla 1)

El segundo plan de inversión consiste en la compra de 700 gallinas, con un valor unitario igual al anterior (\$4.890) en la Avícola Santa Fe (Osorno), además de la construcción y mano de obra de los nidos, que asciende a
Tabla 1. Plan de inversión del primer nivel productivo.

\begin{tabular}{lccc}
\hline \multicolumn{1}{c}{ Ítems } & $\begin{array}{c}\text { Aporte } \\
\text { propio }\end{array}$ & $\begin{array}{c}\text { Crédito } \\
\text { solicitado }\end{array}$ & Total \\
\hline Gallinero & & 8.350 .300 & \\
$\mathrm{~N}^{\circ}$ Gallinas & & 7.968 .000 & \\
Terreno & 1.526 .000 & 395.585 & \\
Cercado & & 210.000 & \\
Nidos & & 16.923 .885 & 18.449 .885 \\
\hline Total & 1.526 .000 & & \\
\hline
\end{tabular}

\$300.000 para la postura de huevos. La fuente de financiamiento es un crédito a largo plazo solicitado a una institución bancaria (Tabla 2)

Tabla 2. Plan de inversión del segundo nivel productivo.

\begin{tabular}{llrl}
\hline \multicolumn{1}{c}{ Ítems } & $\begin{array}{l}\text { Aporte } \\
\text { propio }\end{array}$ & $\begin{array}{c}\text { Crédito } \\
\text { solicitado }\end{array}$ & Total \\
\hline Gallinero & & 8.350 .300 & \\
$\mathrm{~N}^{\circ}$ Gallinas & & 11.952 .000 & \\
Terreno & 1.526 .000 & & \\
Cercado & & 395.585 & \\
Nidos & & 300.000 & \\
\hline Total & 1.526 .000 & 20.997 .885 & 22.523 .885 \\
\hline
\end{tabular}

\section{Descripción de los costos}

Los costos están asociados a la producción de huevos, los cuales se clasifican en costos variables y fijos dependiendo de su variabilidad en relación con el nivel de producción (Lerdon, 2014). El detalle de estos se describe a continuación y presentan en las Tablas 3 y 4.

Costos variables: dentro de los costos variables está el transporte de los huevos para el consumidor, la viruta que es utilizada como piso y cama en el gallinero, el alimento que es comprado en formatos de sacos de $40 \mathrm{~kg}$., bandejas de cartón que son utilizadas para el embalaje del huevo y reparación y mantención de la infraestructura, ya sea el gallinero como el patio de recreación.

- Transporte: en esta sección se considera el costo de la bencina para el transporte de los huevos a la ciudad de Río Negro (un viaje durante el día de lunes a viernes, cada vuelta es de aproximadamente $6 \mathrm{~km}$ ), el costo del cambio de neumáticos una vez al año y cambio de aceite cada $10.000 \mathrm{~km}$, por ende se compra combustible de 93 octanos.

Para el primer nivel productivo se consume alrededor de 150 litros de bencina al año, se 
Tabla 3. Costos totales del primer nivel de producción (400 gallinas).

\begin{tabular}{|c|c|c|c|c|c|c|c|c|}
\hline Costos Variables & Año 0 & Año 1 & Año 2 & Año 3 & Año 4 & Año 5 & Año 6 & Año 7 \\
\hline Transporte & & 249.600 & 250.848 & 252.102 & 253.363 & 254.630 & 255.903 & 257.182 \\
\hline Viruta & & 60.800 & 61.104 & 61.410 & 61.717 & 62.025 & 62.335 & 62.647 \\
\hline Alimento & & 4.745 .000 & 4.768 .725 & 4.792 .569 & 4.816 .531 & 4.840 .614 & 4.864 .817 & 4.889 .141 \\
\hline Trabajador & & 3.120 .000 & 3.151 .200 & 3.182 .712 & 3.214 .539 & 3.246 .685 & 3.279 .151 & 3.311 .943 \\
\hline Bandejas de cartón & & 300.400 & 300.400 & 300.400 & 300.400 & 300.400 & 300.400 & 300.400 \\
\hline $\begin{array}{l}\text { Reparaciones y } \\
\text { Mantención }\end{array}$ & & 80.000 & 80.000 & 80.000 & 80.000 & 80.000 & 80.000 & 80.000 \\
\hline $\begin{array}{l}\text { Sub. Total Costos } \\
\text { Variables }\end{array}$ & & 8.555 .800 & 8.612.277 & 8.669 .192 & 8.726 .550 & 8.784 .353 & 8.842 .607 & 8.901.313 \\
\hline \multicolumn{9}{|l|}{ Costos Fijos } \\
\hline Electricidad & & 700.500 & 703.740 & 706.980 & 710.220 & 713.460 & 716.700 & 719.940 \\
\hline Agua & & 503.000 & 508.030 & 513.110 & 518.241 & 523.424 & 528.658 & 533.945 \\
\hline Teléfono & & 240.000 & 240.000 & 240.000 & 240.000 & 240.000 & 240.000 & 240.000 \\
\hline Depreciación & & 369.035 & 369.035 & 369.035 & 369.035 & 369.035 & 369.035 & 369.035 \\
\hline Sub. Total Costos Fijos & & 1.812 .535 & 1.820 .805 & 1.829 .126 & 1.837 .497 & 1.845 .919 & 1.854 .393 & 1.862 .920 \\
\hline Costos Totales & & 10.368 .335 & 10.433 .082 & 10.498 .318 & 10.564 .047 & 10.630 .273 & 10.697 .000 & 10.764 .233 \\
\hline
\end{tabular}

Tabla 4. Costos totales del segundo nivel de producción (700 gallinas).

\begin{tabular}{|c|c|c|c|c|c|c|c|c|}
\hline Costos Variables & Año 0 & Año 1 & Año 2 & Año 3 & Año 4 & Año 5 & Año 6 & Año 7 \\
\hline Transporte & & 327.600 & 329.238 & 330.884 & 332.539 & 334.201 & 335.872 & 337.552 \\
\hline Viruta & & 106.400 & 106.932 & 107.467 & 108.004 & 108.544 & 109.087 & 109.632 \\
\hline Alimento & & 8.303 .750 & 8.345 .269 & 8.386 .995 & 8.428 .930 & 8.471 .075 & 8.513 .430 & 8.555 .997 \\
\hline Trabajador & & 5.400 .000 & 5.454 .000 & 5.508 .540 & 5.563 .625 & 5.619 .262 & 5.675 .454 & 5.732 .209 \\
\hline Bandejas de cartón & & 525.700 & 525.700 & 525.700 & 525.700 & 525.700 & 525.700 & 525.700 \\
\hline Reparaciones y Mantención & & 140.000 & 140.000 & 140.000 & 140.000 & 140.000 & 140.000 & 140.000 \\
\hline Sub. Total Costos Variables & & 14.803 .450 & 14.901.139 & 14.999 .586 & 15.098 .798 & 15.198 .782 & 15.299 .543 & 15.401 .090 \\
\hline \multicolumn{9}{|l|}{ Costos Fijos } \\
\hline Electricidad & & 1.320 .500 & 1.326 .170 & 1.331 .840 & 1.337 .510 & 1.343 .180 & 1.348 .850 & 1.354 .520 \\
\hline Agua & & 880.250 & 889.053 & 897.943 & 906.922 & 915.992 & 925.152 & 934.403 \\
\hline Teléfono & & 360.000 & 360.000 & 360.000 & 360.000 & 360.000 & 360.000 & 360.000 \\
\hline Depreciación & & 372.635 & 372.635 & 372.635 & 372.635 & 372.635 & 372.635 & 372.635 \\
\hline Sub. Total Costos Fijos & & 2.933.385 & 2.947.858 & 2.962 .418 & 2.977.068 & 2.991.807 & 3.006.637 & 3.021 .559 \\
\hline Costos Totales & & 17.736 .835 & 17.848.997 & 17.962 .004 & 18.075 .866 & 18.190.589 & 18.306 .180 & 18.422 .648 \\
\hline
\end{tabular}

asume un 50\% del costo del cambio de neumáticos (\$100.000), cambio de aceite $(\$ 13.000)$ e imprevistos y reparaciones del vehículo (\$24.100).

Para el segundo nivel productivo se consume alrededor de 187 litros de bencina, ya que se realiza una vuelta más los días martes y viernes, se asume un $75 \%$ del costo del cambio de neumáticos (\$150.000), cambio de aceite $(\$ 13.000)$ e imprevistos y reparaciones del vehículo (\$24.100). El proyecto solo asume un porcentaje de los costos del cambio de neumáticos, ya que el resto lo paga el rubro de la ganadería, debido a que el vehículo también es utilizado para sus actividades.
- Viruta: se compran 202 sacos de viruta al año, los cuales tiene un valor de $\$ 300$ en la barraca en el primer año. Son utilizados para las camas, los nidos y el piso del gallinero, es por esto que deben ser constantemente cambiados para evitar el barrial, enfermedades y formación de malos olores. Para el segundo nivel de producción se necesitan 354 sacos al año con el mismo \$/saco.

- Alimento: el formato del alimento es concentrado en sacos de $40 \mathrm{~kg}$, y compuesto por maíz, maravilla, soya, vitaminas, sales minerales y conchuelas. El valor es de 325 \$/ $\mathrm{kg}$ de alimento, es decir el saco tiene un precio 
de $\$ 13.000$ (bruto), ocupando al año 366 sacos para el primer nivel productivo y 639 sacos al año en el segundo nivel productivo. Todo esto complementado con praderas.

- Trabajador: para las labores productivas del día, se cuenta con un trabajador, cuya jornada es de 5 horas diarias para el primer nivel productivo y 7 horas diarias para el segundo nivel productivo. El sueldo para el primer nivel productivo es de $\$ 300.000$ mensuales y de $\$ 450.000$ mensuales para el segundo nivel productivo.

- Bandejas de cartón: las bandejas vienen en formatos de 12 y 30 unidades, en el primer nivel productivo el costo es de $\$ 300.400$ y de $\$ 525.700$ para el segundo nivel productivo.

- Reparaciones y mantenciones: este ítem consiste en la reparación y mantención del gallinero y el cercado, en el primer nivel se calculó en promedió un valor de $\$ 80.000$ y el segundo nivel productivo un valor de $\$ 140.000$; esto ya que al existir mayor número de gallinas la probabilidad de daño y reparaciones es mayor.

Costos fijos. Dentro de los costos fijos se encuentra la electricidad que se utiliza en el gallinero para estimular la producción de huevos, el agua, la cuenta del teléfono incluido el internet para el contacto con los consumidores y la depreciación del activo fijo.

- Electricidad: la electricidad es utilizada de forma periódica en el gallinero para simular las horas de luz necesarias que deben tener las gallinas y así mantener la producción tanto en invierno como en verano. Para el primer nivel productivo este costo es de $\$ 700.500$ en el primer año (4 focos de luz) y de $\$ 1.320 .500$ para el segundo nivel (6 focos de luz).

- Agua: para el cálculo del agua se aplicó el criterio por asignación de ingresos, es decir el fundo trabaja netamente con ganadería, es por esto que el agua que utiliza el gallinero corresponde solamente al $40 \%$ del total que utiliza el fundo. Este costo es de \$503.000 para el primer nivel productivo (4 bebederos) y de $\$ 880.250$ para el segundo nivel productivo (7 bebederos).

- Teléfono: el teléfono e internet es utilizado exclusivamente para el contacto con los consumidores y proveedor de las cajas donde es embalado el producto. El plan es \$20.000 mensuales para el primer nivel y de $\$ 30.000$ mensuales para el segundo nivel.

- Depreciación: la depreciación de los activos fijos incluye el gallinero, el estanque de agua, el pozo, los nidos y el cercado. Para la depreciación de la bomba (del pozo) y el estanque, solo se asume un $40 \%$ del costo total, ya es que el resto lo asume la actividad de la ganadería.

\section{Descripción de ingresos}

El principal ingreso es la comercialización de los huevos (el porcentaje de postura es de un $90 \%$ por gallina, se consideró un $7 \%$ de pérdidas de producción diarias y $5 \%$ de gallinas muertas), el cual depende del precio de venta de la unidad, que en este caso es un $20 \%$ mayor que el del huevo producido convencionalmente, debido a que aumentan los costos de inversión para la implementación de este sistema y además que los consumidores están dispuestos a pagar si se asegura el bienestar de las aves.

Según lo señalado por Brown (2016), no debe ser sorpresa que los productores en la transición a un funcionamiento sin jaula, pueden esperar mayores costos; el estudio CSES encontró que los sistemas libres de jaulas cuestan un 36\% más de operar, y el mayor costo de los huevos libres de jaulas deben ser transferidos a los consumidores.

En ambos casos el precio de venta es de $\$ 135$ en época de verano, que se extiende desde el mes de septiembre hasta abril, y $\$ 140$ entre mayo y agosto. El resto de los ingresos corresponde a la venta de gallinas de deshecho al término del ciclo productivo y el guano de gallina para fertilización.

\section{Proyección de fuentes y usos de fondos}

La inversión inicial se financia con un crédito a largo plazo en una institución financiera con una tasa de interés de 9,48\%, utilizando el mismo valor para la tasa de descuento. En la tabla 5 se puede observar que los saldos anuales son positivos, considerándose retiros privados de $\$ 3.000 .000$ en el primer año, mejorando los flujos en los siguientes años. Los retiros personales para el segundo, tercero, cuarto y quinto año son iguales $(\$ 4.000 .000)$ y aumentan para el sexto $(\$ 5.000 .000)$ y septimo año $(\$ 7.000 .000)$ (Tabla 5).

Para el segundo nivel productivo (Tabla 6), los saldos anuales también son positivos, con mayores ingresos desde el primer año, en comparación con el nivel anterior. Asimismo, se considera un retiro privado de $\$ 5.000 .000$ el primer año, cifra que aumenta paulatinamente hasta estabilizarse en 12.000.000 en el sexto año (Tabla 6) 
Tabla 5. Proyección de fuentes y usos de fondos del primer nivel productivo.

\begin{tabular}{|c|c|c|c|c|c|c|c|c|}
\hline Fuentes & Año 0 & Año 1 & Año 2 & Año 3 & Año 4 & Año 5 & Año 6 & Año 7 \\
\hline Ingresos Netos & & 6.755 .085 & 7.544 .385 & 7.193 .226 & 7.981 .605 & 7.629 .517 & 8.416 .958 & 8.063 .925 \\
\hline Depreciación & & 369.035 & 369.035 & 369.035 & 369.035 & 369.035 & 369.035 & 369.035 \\
\hline Crédito solicitado & 16.923 .885 & & & & & & & \\
\hline Aporte de capital & 1.526 .000 & & & & & & & \\
\hline Valor residual & & & & & & & & 6.642 .637 \\
\hline Total & 18.449 .885 & 7.124.120 & 7.913 .420 & 7.562.261 & 8.350 .640 & 7.998.552 & 8.785 .993 & 15.075.597 \\
\hline \multicolumn{9}{|l|}{ Usos } \\
\hline Inversión Activo Fijo & 18.449 .885 & & & & & & & \\
\hline Amort. Crédito Solicitado & & 1.812 .577 & 1.984 .409 & 2.172 .531 & 2.378 .487 & 2.603 .967 & 2.850 .824 & 3.121 .082 \\
\hline Intereses Crédito solicitado & & 1.604 .384 & 1.432 .552 & 1.244 .430 & 1.038 .474 & 812.994 & 566.137 & 295.879 \\
\hline Retiros Personales & & 3.000 .000 & 4.000 .000 & 4.000 .000 & 4.000 .000 & 4.000 .000 & 5.000 .000 & 7.000 .000 \\
\hline Total & 18.449 .885 & 6.416 .961 & 7.416.961 & 7.416 .961 & 7.416 .961 & 7.416 .961 & 8.416 .961 & 10.416 .961 \\
\hline Saldo Anual & $\mathbf{0}$ & 707.159 & 496.459 & 145.300 & 933.679 & 581.591 & 369.032 & 4.658.636 \\
\hline
\end{tabular}

Tabla 6. Proyección de fuentes y usos de fondos del segundo nivel productivo.

\begin{tabular}{|c|c|c|c|c|c|c|c|c|}
\hline Fuentes & Año 0 & Año 1 & Año 2 & Año 3 & Año 4 & Año 5 & Año 6 & Año 7 \\
\hline Ingresos Netos & & 9.813 .595 & 11.686 .425 & 12.323 .439 & 14.194 .629 & 14.829 .988 & 16.699 .510 & 17.333 .187 \\
\hline Depreciación & & 372.635 & 372.635 & 372.635 & 372.635 & 372.635 & 372.635 & 372.635 \\
\hline Crédito solicitado & 20.997 .885 & & & & & & & \\
\hline Aporte de capital & 1.526 .000 & & & & & & & \\
\hline Valor residual & & & & & & & & 6.707 .437 \\
\hline Total & 22.523.885 & 10.186 .230 & 12.059 .060 & 12.696.074 & 14.567.264 & 15.202 .624 & 17.072.146 & 24.413.259 \\
\hline \multicolumn{9}{|l|}{ Usos } \\
\hline Inversión Activo Fijo & 22.523 .885 & & & & & & & \\
\hline Amort. Crédito Solicitado & & 2.248 .910 & 2.462 .107 & 2.695 .515 & 2.951 .049 & 3.230 .809 & 3.537 .090 & 3.872 .406 \\
\hline Intereses Crédito solicitado & & 1.990 .599 & 1.777 .403 & 1.543 .995 & 1.288 .460 & 1.008 .701 & 702.420 & 367.104 \\
\hline Retiros Personales & & 5.000 .000 & 7.000 .000 & 8.000 .000 & 10.000 .000 & 10.000 .000 & 12.000 .000 & 12.000 .000 \\
\hline Total & 22.523.885 & 9.239 .510 & 11.239.510 & 12.239 .510 & 14.239 .510 & 14.239 .510 & 16.239 .510 & 16.239 .510 \\
\hline Saldo Anual & $\mathbf{0}$ & 946.720 & 819.551 & 456.564 & 327.755 & 963.114 & 832.636 & 8.173 .750 \\
\hline
\end{tabular}

\section{Flujo de ingresos y costos para la evaluación financiera}

En la tabla 7 se presenta el flujo de caja del primer nivel productivo, con una inversión de $\$ 18.449 .885$, que incluye la implementación del sistema alternativo. El terreno es aportado por el propietario del predio, como se indica en el plan de inversión (Tabla 7).

Para el segundo nivel (Tabla 8) ocurre algo similar, con la diferencia que como se cuenta con mayor producción, los ingresos brutos son mayores al igual que los costos anuales. La inversión también es mayor (\$22.523.885) por la compra de más nidos y de las 700 gallinas en un comienzo y el reemplazo de estas en los años posteriores (segundo, cuarto y sexto) (Tabla 8).

\section{Evaluación económica}

En las tablas 9 y 10 se presentan los antecedentes y resultados del cálculo del valor actual de los beneficios netos (VABN) y tasa interna de retorno (TIR) para ambos niveles productivos. Para el primer nivel (400 gallinas), el VABN es de $\$ 24.420 .465$ y la TIR de un $39 \%$, mientras que para el segundo nivel (700 gallinas) se obtuvo un VABN de $\$ 49.187 .725$ y una TIR de $52 \%$, siendo ambos proyectos rentables, con mejores indicadores para el segundo. La tasa de descuento en ambos niveles fue de un 9,48\%. (Tablas 9 y 10).

En indicadores complementarios, como la relación beneficiocosto, se obtuvo un valor de 1,24 para el primer nivel productivo, lo que evidencia que por cada peso invertido se gana 0,24 pesos. Este indicador, para el segundo nivel, fue de 1,29. 
Tabla 7. Flujo de ingresos y costos del primer nivel productivo.

\begin{tabular}{|c|c|c|c|c|c|c|c|c|}
\hline Ítem & Año 0 & Año 1 & Año 2 & Año 3 & Año 4 & Año 5 & Año 6 & Año 7 \\
\hline Ingresos Brutos & & 17.162 .820 & 18.016 .867 & 17.730 .944 & 18.585 .051 & 18.299 .189 & 19.153 .358 & 18.867 .558 \\
\hline - Costos Anuales & & 10.368 .335 & 10.433 .082 & 10.498 .318 & 10.564 .047 & 10.630 .273 & 10.697 .000 & 10.764 .233 \\
\hline Utilidad Bruta & & 6.794 .485 & 7.583.785 & 7.232.626 & 8.021 .005 & 7.668.917 & 8.456 .358 & 8.103.325 \\
\hline - Contribuciones & & 39.400 & 39.400 & 39.400 & 39.400 & 39.400 & 39.400 & 39.400 \\
\hline Utilidad Neta & & 6.755 .085 & 7.544 .385 & 7.193 .226 & 7.981 .605 & 7.629 .517 & 8.416 .958 & 8.063 .925 \\
\hline Depreciación & & 369.035 & 369.035 & 369.035 & 369.035 & 369.035 & 369.035 & 369.035 \\
\hline Inversión Total & -18.449 .885 & & & & & & & \\
\hline Valor Residual & & & & & & & & 6.642 .637 \\
\hline Flujo De Caja & -18.449 .885 & 7.124 .120 & 7.913 .420 & 7.562 .261 & 8.350 .640 & 7.998 .552 & 8.785 .993 & 15.075 .597 \\
\hline
\end{tabular}

Tabla 8. Flujo de ingresos y costos del segundo nivel productivo.

\begin{tabular}{|c|c|c|c|c|c|c|c|c|}
\hline Ítem & Año 0 & Año 1 & Año 2 & Año 3 & Año 4 & Año 5 & Año 6 & Año 7 \\
\hline Ingresos Brutos & & 27.589 .830 & 29.574 .822 & 30.324 .843 & 32.309 .895 & 33.059 .977 & 35.045 .091 & 35.795 .235 \\
\hline Costos Anuales & & 17.736 .835 & 17.848 .997 & 17.962 .004 & 18.075 .866 & 18.190 .589 & 18.306 .180 & 18.422 .648 \\
\hline Utilidad Bruta & & 9.852 .995 & 11.725 .825 & 12.362 .839 & 14.234 .029 & 14.869 .388 & 16.738 .910 & 17.372.587 \\
\hline - Contribuciones & & 39.400 & 39.400 & 39.400 & 39.400 & 39.400 & 39.400 & 39.400 \\
\hline Utilidad Neta & & 9.813 .595 & 11.686 .425 & 12.323 .439 & 14.194 .629 & 14.829 .988 & 16.699 .510 & 17.333 .187 \\
\hline Depreciación & & 372.635 & 372.635 & 372.635 & 372.635 & 372.635 & 372.635 & 372.635 \\
\hline Inversión Total & -22.523 .885 & & & & & & & \\
\hline Valor Residual & & & & & & & & 6.707.437 \\
\hline Flujo De Caja & -22.523 .885 & 10.186 .230 & 12.059 .060 & 12.696 .074 & 14.567 .264 & 15.202 .624 & 17.072 .146 & 24.413 .259 \\
\hline
\end{tabular}

Tabla 9. Indicadores VABN y TIR para el primer nivel productivo

\begin{tabular}{cccccc}
\hline Ã̃NO & $\begin{array}{c}\text { Monto } \\
\text { Inversión }\end{array}$ & $\begin{array}{c}\text { Utilidad Neta }+ \\
\text { Depreciación }\end{array}$ & $\begin{array}{c}\text { Valor } \\
\text { Residual }\end{array}$ & Saldo & $\begin{array}{c}\text { Actualizado } \\
(\mathbf{9 , 4 8})\end{array}$ \\
\hline 0 & -18.449 .885 & & -18.449 .885 & -18.449 .885 \\
1 & 7.124 .120 & 7.124 .120 & 6.507 .234 \\
2 & 7.913 .420 & 7.913 .420 & 6.602 .291 \\
3 & 7.562 .261 & 7.562 .261 & 5.762 .983 \\
4 & 8.350 .640 & 8.350 .640 & 5.812 .736 \\
5 & 7.998 .552 & 7.998 .552 & 5.085 .544 \\
6 & 8.785 .993 & 8.785 .993 & 5.102 .490 \\
7 & 8.432 .960 & 6.642 .637 & 15.075 .597 & 7.997 .072 \\
\hline & VABN & & 24.420 .465 \\
\hline
\end{tabular}

Tabla 10. Indicadores VABN y TIR para el segundo nivel productivo

\begin{tabular}{|c|c|c|c|c|c|}
\hline AÑO & $\begin{array}{c}\text { Monto } \\
\text { Inversión }\end{array}$ & $\begin{array}{c}\text { Utilidad Neta + } \\
\text { Depreciación }\end{array}$ & $\begin{array}{c}\text { Valor } \\
\text { Residual }\end{array}$ & Saldo & $\begin{array}{c}\text { Actualizado } \\
(9,48)\end{array}$ \\
\hline 0 & -22.523 .885 & & & -22.523 .885 & -22.523 .885 \\
\hline 1 & & 10.186 .230 & & 10.186 .230 & 9.304 .193 \\
\hline 2 & & 12.059 .060 & & 12.059 .060 & 10.061 .063 \\
\hline 3 & & 12.696 .074 & & 12.696 .074 & 9.675 .314 \\
\hline 4 & & 14.567 .264 & & 14.567 .264 & 10.140 .021 \\
\hline 5 & & 15.202 .624 & & 15.202 .624 & 9.665 .951 \\
\hline 6 & & 17.072 .146 & & 17.072 .146 & 9.914 .695 \\
\hline \multirow[t]{3}{*}{7} & & 17.705 .822 & 6.707 .437 & 24.413 .259 & 12.950 .372 \\
\hline & & VABN & & & 49.187 .725 \\
\hline & & TIR & & & 52,71 \\
\hline
\end{tabular}


Con respecto al período de recuperación del capital, al considerar una tasa de descuento de 9,48\% para ambos niveles, la inversión se recupera al final del tercer año para el primer nivel. En el segundo nivel de producción la inversión tambien se recupera en el tercer año, pero en el primer mes.

El punto de equilibrio, o porcentaje de los ingresos que cubren los costos totales y a partir del cual se generan las utilidades, para el primer nivel productivo fluctúa entre un $21 \%$ el primer año y un $19 \%$ en el año 5, cuando se estabiliza, con un promedio para los 7 años analizados en un 19\% (Tabla 11).

Para el segundo nivel productivo (Tabla 12), el punto de equilibrio fluctua entre un $23 \%$ para el primer año y un $15 \%$ en el año 6 , con un promedio de $18 \%$ en los años del proyecto (Tabla 12).

\section{Análisis unidimensional de la sensibilización del VABN y riesgo del proyecto}

La evaluación del proyecto será sensible a las variaciones de uno o más parámetros si, al incluir estas variaciones en el criterio de evaluación empleado, la decisión inicial cambia (Sapag y Sapag, 2008).

En este caso el parámetro más determinante en los ingresos es el precio del huevo, ya que a un mismo nivel de producción, es el que genera mayores beneficios anualmente. En la tabla 13 se detalla el efecto de la disminución parcial del precio del huevo en el VABN, hasta que este se hace negativo.

Para el primer nivel productivo el VABN se hace negativo cuando se disminuye en un $25 \%$ el precio del huevo, deduciéndose que puede bajar hasta un $24 \%$ aproximadamente y seguirá siendo rentable (Tabla 13).
Para el segundo nivel productivo, en la tabla 14 se observa una mayor tolerancia a la baja porcentual del precio del huevo y su efecto en el VABN, indicador que se hace negativo con un $27 \%$ de disminución (Tabla 14).

Dadas las características de este proyecto, la variable que más podría influir en su rentabilidad es el precio del huevo. El análisis de sensibilidad realizado indica que el precio debería disminuir en un 25 y $27 \%$ respectivamente, en ambos niveles productivos, para que el proyecto deje de ser rentable. Si se considera que en los últimos años el precio del huevo ha sido permanentemente al alza, podría concluirse que, desde este punto de vista, el riesgo del proyecto es bajo.

No obstante, el riesgo de este proyecto no solo se puede asociar a la disminución del precio del huevo, sino también a otros factores como competidores futuros dentro de la zona, aumento del precio del alimento de las aves, etc. Pero son menos probables, el precio del huevo producido bajo este sistema alternativo, es más alto que el de aquellos producidos convencionalmente (jaulas), pero los consumidores están dispuestos a pagar debido a la gran demanda de productos que estén ligados al bienestar animal y a la bioseguridad.

\section{Conclusiones}

La producción de huevos a nivel mundial ha crecido en forma sostenida en los últimos años. Este aumento se ha dado por el crecimiento notable de los países asiáticos, especialmente China.

La producción de huevos en Chile también va en aumento con 196.820 toneladas en la actualidad,

Tabla 11. Punto de equilibrio del primer nivel productivo.

\begin{tabular}{cccccc}
\hline Año & Costos totales & Costos fijos & $\begin{array}{c}\text { Costos } \\
\text { variables }\end{array}$ & $\begin{array}{c}\text { Ingreso } \\
\text { bruto }\end{array}$ & $\begin{array}{c}\text { Punto de } \\
\text { equilibrio }\end{array}$ \\
\hline 0 & - & - & - & - & $0 \%$ \\
1 & 10.368 .335 & 1.812 .535 & 8.555 .800 & 17.162 .820 & $21 \%$ \\
2 & 10.433 .082 & 1.820 .805 & 8.612 .277 & 18.016 .867 & $19 \%$ \\
3 & 10.498 .318 & 1.829 .126 & 8.669 .192 & 17.730 .944 & $20 \%$ \\
4 & 10.564 .047 & 1.837 .497 & 8.726 .550 & 18.585 .051 & $18 \%$ \\
5 & 10.630 .273 & 1.845 .919 & 8.784 .353 & 18.299 .189 & $19 \%$ \\
6 & 10.697 .000 & 1.854 .393 & 8.842 .607 & 19.153 .358 & $19 \%$ \\
7 & 10.764 .233 & 1.862 .920 & 8.901 .313 & 18.867 .558 & $19 \%$ \\
\hline & PROMEDIO & & & & $19 \%$ \\
\hline
\end{tabular}


Tabla 12 . Punto de equilibrio del segundo nivel productivo.

\begin{tabular}{cccccc}
\hline Año & $\begin{array}{c}\text { Costos } \\
\text { totales }\end{array}$ & $\begin{array}{c}\text { Costos } \\
\text { fijos }\end{array}$ & $\begin{array}{c}\text { Costos } \\
\text { variables }\end{array}$ & $\begin{array}{c}\text { Ingreso } \\
\text { bruto }\end{array}$ & $\begin{array}{c}\text { Punto de } \\
\text { equilibrio }\end{array}$ \\
\hline 0 & - & - & - & - & $0 \%$ \\
1 & 17.736 .835 & 2.933 .385 & 14.803 .450 & 27.589 .830 & $23 \%$ \\
2 & 17.848 .997 & 2.947 .858 & 14.901 .139 & 29.574 .822 & $20 \%$ \\
3 & 17.962 .004 & 2.962 .418 & 14.999 .586 & 30.324 .843 & $19 \%$ \\
4 & 18.075 .866 & 2.977 .068 & 15.098 .798 & 32.309 .895 & $17 \%$ \\
5 & 18.190 .589 & 2.991 .807 & 15.198 .782 & 33.059 .977 & $17 \%$ \\
6 & 18.306 .180 & 3.006 .637 & 15.299 .543 & 35.045 .091 & $15 \%$ \\
7 & 18.422 .648 & 3.021 .559 & 15.401 .090 & 35.795 .235 & $15 \%$ \\
\hline \multicolumn{7}{r}{ Promedio } & & & & $18 \%$ \\
\hline
\end{tabular}

Tabla 13 . Análisis de sensibilidad del primer nivel productivo.

\begin{tabular}{ccc}
\hline $\begin{array}{c}\text { Porcentaje de } \\
\text { disminución }\end{array}$ & $\begin{array}{c}\text { Precio del } \\
\text { huevo }\end{array}$ & VABN \\
\hline $0 \%$ & $135-140$ & 24.420 .465 \\
$4 \%$ & $130-135$ & 16.940 .131 \\
$11 \%$ & $120-125$ & 10.800 .764 \\
$18 \%$ & $110-115$ & 4.661 .396 \\
$25 \%$ & $100-105$ & -1.477 .972 \\
\hline
\end{tabular}

concentrándose en la zona central del país. En cuanto a la producción de sistemas alternativos, en Chile no existe mayor información, ya que las producciones mencionadas son estadísticas manejadas bajo los sistemas convencionales (con jaulas).

Otro parámetro que ha ido en aumento es la preocupación por el bienestar animal, por lo cual en el año 2012 la UE prohibió la utilización de jaulas por medio de una legislación para sus productores. Gracias a esto, existe una diversificación de los sistemas de producción, siendo uno de ellos el sistema alternativo (sin jaulas) o free-range.

Otro tema es la mayor inversión inicial y el aumento de los costos de producción para el sistema alternativo, ya que se requiere de mayor infraestructura y espacio para su instalación, y por último el parámetro mas importante y que hace la diferencia para los consumidores es el precio del huevo, siendo mucho mayor en el sistema fre-range, debido a que los costos de producirlo también son mayores. Es ahí donde radica la gran diferencia, pero los consumidores están dispuesto a pagar y así lo confirma la masiva preocupación del bienestar animal que se constató en el estudio.

En Chile las proyecciones de la oferta estimadas para el año 2020 son de 218.008 toneladas y las
Tabla 14. Análisis de sensibilidad del segundo nivel productivo.

\begin{tabular}{ccc}
\hline $\begin{array}{c}\text { Porcentaje de } \\
\text { disminución }\end{array}$ & $\begin{array}{c}\text { Precio del } \\
\text { huevo }\end{array}$ & VABN \\
\hline $0 \%$ & $135-140$ & 49.187 .725 \\
$4 \%$ & $130-135$ & 43.364 .901 \\
$11 \%$ & $120-125$ & 32.170 .787 \\
$18 \%$ & $110-115$ & 20.976 .673 \\
$25 \%$ & $100-105$ & 9.295 .442 \\
$27 \%$ & $90-95$ & -1.298 .672 \\
\hline
\end{tabular}

proyecciones para la demanda indican que el consumo aparente por persona también para el año 2020 será de 197 huevos.

La inversión del proyecto para el primer nivel productivo es de $\$ 18.449 .885$ y para el segundo nivel productivo es de $\$ 22.523 .885$, asociados específicamente a la construcción del gallinero (equipado), cerco, nidos y la compra de las gallinas de raza Loman Brown.

La evaluación financiera y económica revela que para el séptimo año los ingresos netos son de $\$ 8.063 .925$, para el primer nivel productivo y de $\$ 17.333 .187$ para el segundo nivel. En cuanto a los indicadores económicos la evaluación indica que para el primer nivel el VABN es de $\$ 24.420 .465$ y para el segundo nivel productivo el VABN es de $\$ 49.187 .725$, siendo ambos niveles rentables, con una tasa de descuento de $9,48 \%$. La TIR es de un $39 \%$ y $52 \%$ respectivamente para ambos niveles de producción, lo que reafirma que el proyecto es factible en ambos casos.

Sin embargo, el segundo nivel (700 gallinas) sería más atractivo, con mejores indicadores económicos, beneficios y retiros personales más altos desde el primer año y una mayor tolerancia a una eventual disminución en el precio del huevo. 


\section{Literatura citada}

Albarrán, P.; Cruz-Coke, M.; Gandarillas, M.

2011. Sistema free range o sistema alternativo la nueva forma de producir huevos. Revista Agronomía y Forestal UC(Chile), 41: 30 - 35.

Anastasov, M.

2014. Sistema free-range la otra manera de producir huevos. Revista Tattersall (Chile), 231: 18-20.

Anderson, K. E.

2009. Overview of natural and organic egg production: looking back to the future. J. Appl. North Carolina State University, Res: 18: 348 - 354.

Asociación gremial de Productores de huevo de Chile (ASOHUEVO). 2016. ¿Quienes somos?, Asociados (On line). <http:// www.chilehuevos.cl/industria/asohuevo/asociados.html> Consultado: 22/mar/2016.

Asociación gremial de Productores de huevo de Chile (ASOHUEVO). 2014. Precios Productor sin IVA publicados por Revista del Campo de El Mercurio. Disponible: <http://www.chilehuevos. cl/industria/industria/precios.html > Consultao: 25/jul/2015.

Brown, J.

2016. Cage-free hen housing: How far will the pendulum swing?. Disponible en: <http://poultryhealthtoday.com/cagefree-hen-housing-far-will-pendulum-swing/> Consultado: 29/may/2016

Callejos, A.

2012. Impacto de la nueva normativa europea en la producción de huevos. Depto. de Producción Animal, Universidad Politécnica de Madrid, España. INDUSTRIA AVICOLA. PAG 8 - 11. Disponible en: http://www.wattagnet.com/ articles/12568-impacto-de-la-nueva-normativa-europea-en la-producción-de-huevos Consultado: 29/abr/2016.

Giacomozzi, J.

2014. Panorama y actualización del mercado del huevo. Oficina de estudios y políticas agrarias. Santiago, Chile. 6p.
Evans, T.

2015. Americas Supply One-fifth of World's Eggs. Disponible: http://www.thepoultrysite.com/articles/3364/global-poultrytrends-americas-supply-onefifth-of-worlds-eggs/ Consultado: 29/abr/2016.

Giacomozzi, J.

2014. Situación actual de la industria del huevo. Oficina de estudios y políticas agrarias. Santiago, Chile. $8 \mathrm{p}$.

Graber, R.

2016. Infographic: 103 food industry brands to pledge cage free in 2016. Disponible: http://www.wattagnet.com/ articles/26752-infographic---cage-free-eggcommitments Consultado: 29/abr/2016.

Graber, R.

2016. Infographic: Companies pledging to use cage-free eggs. Disponible: http://www.wattagnet.com/articles/25540infographic-companies-pledging-to-use-cage-free-eggs Consultado: 29/abr/2016.

Magdeleine, P.; Gonnier, V.; Jez, C.

2011. Situación, perspectivas y retos para los sectores europeos del huevo a las puerta del 2012. Selecciones Avícolas, 53 (10): 7-15.

Mench J.A.; Swanson, J.C.; Thompson, P.B.

2009. Laying Hen Production Systems: Welfare and Social Sustainability. Proceedings of 8th Poultry Welfare Symposium, Cervia, Italy. pp: 2-3.

United State Departament Of Agriculture (Usda).

2012. EU Animal Welfare for Laying Hens. International egg and poultry review, 15 (9): $1-3$.

USA, FOOD AND AGRICULTURAL ORGANIZATION (FAO)

2015. El huevo en cifras. Disponible: http://www.fao.org/ resources/infographics/infographics-details/es/c/284415/ Consultado: 28/ago/2015. 